
SUSUNAN DEWAN REDAKSI

“JURNAL NASIONAL KOMPUTASI DAN TEKNOLOGI INFORMASI (JNKTI)"

\author{
Penanggung Jawab \\ Muhammad Fadhli, S.Kom, M.Kom \\ Ketua Dewan Editor \\ Zulfan, ST, MT \\ Editor Pelaksana \\ Munawir, ST, MT \\ Baihaqi, ST, MT \\ Sekretaris \\ Yeni Yanti, ST, MT \\ Mitra Bestari \\ Prof. Dr. Ir. Yuwaldi Away, M.Sc \\ Dr. Taufiq A. Gani, S.Kom, M.Eng.Sc \\ Dr. Melinda, ST, M.Sc \\ Layout \\ Eka Novendra, ST \\ Penerbit \\ Program Studi Teknik Informatika \\ Universitas Serambi Mekkah \\ Alamat Penerbit
}

Gedung H Fakultas Teknik Universitas Serambi Mekkah

Jl. T. Imum Lueng Bata, Telp. (0651)26160 Batoh - Banda Aceh 


\section{SINOPSIS}

Jurnal Nasional Komputasi dan Teknologi Informasi (JNKTI) merupakan jurnal ilmiah nasional yang diterbitkan oleh Program Studi Teknik Informatika Universitas Serambi Mekkah yang mempublikasikan artikel-artikel ilmiah dalam bidang komputasi dan teknologi informasi.Jurnal ini terbit sebanyak 2 (dua) kali dalam 1 (satu) tahun yaitu pada Bulan April dan Oktober. Bidang-bidang fokus penelitian yang akan dipublikasi dalam jurnal ini antara lain :

- Bidang Rekayasa Perangkat Lunak

- Bidang Jaringan Komputer

- Bidang Multimedia dan Pengolahan Citra Digital

- Bidang Komputasi

- Multidisiplin ilmu lainnya yang relevan 
DAFTAR ISI

JNKTI VOL.2 NO.1, APRIL 2019

Studi Simulasi Aerodinamika Airfoil dan Prediksi

$1-8$

Performa Picth Tetap Turbin Angin Poros Tegak (Darrieus)

terhadap Output Power untuk Aplikasi Kecepatan Angin Rendah

Wahyu Priyanto ${ }^{1}$, Ira Devi Sara ${ }^{2}$, Rakhmad Syafutra Lubis ${ }^{3}$

Analisis Performansi Video Streaming Dengan Menggunakan

$9-12$

Protokol RTSP Pada Jaringan IEEE 802.11n

Rahmad Rizki ${ }^{1}$, Rizal Munadi ${ }^{2}$, Syahrial $^{2}$

Pengaruh Heatsink Terhadap Kinerja Modul Surya

$13-18$

T. Mizan Sya'rani D. ${ }^{1 *}$, Ira Devi Sara ${ }^{2}$, dan Laina Hilma Sari ${ }^{3}$

Penentuan Tingkat Penyebaran Ikan Berdasarkan Citra

Suhu Permukaan Laut Di Perairan Laut Kabupaten Aceh Jaya

Menggunakan Satelit Aqua Modis

Naziran ${ }^{1}$, Rizal Munadi ${ }^{2}$, Muchlisin ${ }^{2}$

Studi Pengaruh Hibridisasi Seleksi Roullete Wheel Dengan $26-30$

Tournament Selection Menggunakan Algoritma Berevolusi Pada TSP

Cut lilis Setiawati ${ }^{1}$, Taufiq Abdul Gani ${ }^{2}$, Yuwaldi Away ${ }^{2}$

Audit Dan Optimasi Energi Listrik Pada Bangunan Kampus $31-37$

Menggunakan Metode Algoritma Genetika

Samsuddin $^{1}$, Suriadi ${ }^{2}$, Yuwaldi Away ${ }^{3}$

Aplikasi Histogram Discrete Cosine Transform (DCT) Untuk $38-42$

Sistem Temu Kembali Citra Termal Berbasis Konten

Faridah $^{1}$, Khairul Munadi ${ }^{2}$, Fitri Arnia ${ }^{3}$

Pengujian Algoritma Artificial Neural Network (ANN) $43-47$

Untuk Prediksi Kecepatan Angin

Syukri $^{1}$, Samsuddin ${ }^{2}$

Penerapan Information Retrieval Menggunakan Pemodelan $48-54$

Topik Pada Deskripsi Portal Multimedia

Indra Gita Anugrah ${ }^{1}$ dan Harunur Rosyid ${ }^{2}$

Analisa Steganografi untuk Citra Bewarna (RGB)

Menggunakan Metode Less Significant Bit (LSB)

Raihan Islamadina $^{1}$, Baihaqi $^{2}$, dan Mauzar sulistriadi ${ }^{3}$ 


\title{
Penentuan Tingkat Penyebaran Ikan Berdasarkan Citra Suhu Permukaan Laut Di Perairan Laut Kabupaten Aceh Jaya Menggunakan Satelit Aqua Modis
}

\author{
Naziran $^{1}$, Rizal Munadi ${ }^{2}$, Muchlisin $^{2}$ \\ ${ }^{1}$ Magister Teknik Elektro, Universitas Syiah Kuala \\ ${ }^{2}$ Program Studi Teknik Elekro dan Komputer \\ Fakultas Teknik Universitas Syiah Kuala \\ *Koresponden email: naziranmte@gmail.com
}

\begin{abstract}
Abstrak
Potensi ikan atau tangkapan di perairan laut Kabupaten Aceh Jaya cukup besar tetapi belum dapat memberikan manfaat yang baik kepada masyarakat khususnya nelayan-nelayan tradisional di pesisir garis pantai Aceh Jaya. Potensi seluruh kekayaan area garis pantai kawasan Aceh Jaya tertutupi oleh permukaan air laut, perlu dikaji dan dipecahkan dalam menjawab terhadap keberangaman sumberdaya biota laut khususnya areal kantungkantung ikan di lingkungan Pulo Ranggah dan sekitarnya. Teknologi penginderaan jauh sangat tepat digunakan dalam penelitian ini, bertujuan untuk mengetahui sebaran klorofil-a, suhu permukaan laut dan total karbon organik terhadap prediksi area tangkapan ikan dengan alat tangkap pancing ulur, serta memanfaatkan data citra satelit Aqua MODIS level-3 di perairan Kabupaten Aceh Jaya. Tahapan-tahapan yang dilakukan, pengumpulan citra, pemotongan citra pada koordinat area tangkapan yang diinginkan. Terhadap infomasi kandung klorofila, suhu permukaan laut dan total karbon organik dapat dilakukan interpolasi dengan menggunakan perangkat lunak SeaDAS. Metode yang digunakan dalam tahapan penelitian ini adalah metode deskripsif dan metode analisis data menggunakan analisis regresi linear berganda. Citra satelit yang digunakan Aqua MODIS dengan resolusi spasial $4 \mathrm{Km} 2$ dan temporal bulanan. Secara umum area yang selalu memiliki konsentrasi klorofil-a tinggi, dan kandungan total karbon organik dapat diindikasikan kawasan tersebut kaya dengan ikan.
\end{abstract}

Kata kunci : Kawasan areal pengankapan ikan, remote sensing, Satelit Aqua Modis

\section{Pendahuluan}

Kabupaten Aceh Jaya, yang didirikan pada tahun 2002 merupakan pemekaran dari Kabupaten induk yaitu Kabupaten Aceh Barat (Meulaboh), hingga tahun 2018 mempunyai wilayah administrasi bawahan 9 Kecamatan, 21 Mukim dan 172 Desa. Ibukota Kabupaten terletak di Calang. Sumberdaya alam ikan ini merupakan salah satu sumber makanan dan sumber mata pencaharian nelayan tradisional di Indonesia, khusunya nelayan Kabupaten Aceh Jaya. Sumberdaya perikanan merupakan salah satu sumber makanan dan mata pencaharian yang penting di berbagai belahan negara. Namun, seiring dengan perkembangan ekonomi dan pertumbuhan populasi manusia di Indonesia, tekanan dan kebutuhan terhadap sumberdaya perikanan juga meningkat. Hal ini membutuhkan perhatian dari pemerintah agar dapat melakukan berbagai kebijakan untuk meminimalkan dampak negatif yang mungkin timbul [1-2]

Namun penelitian tentang area tangkapan ikan belum pernah dilakukan pada kawasan Pulau Ranggah. Informasi yang didapatkan dari nelayan tradisional, selama ini hasil tangkapan nelayan jenis ikan karang menurut, mungkin diakibatkan oleh suhu yang panas, pola megrasi ikan, areanya tercemaran, penurunan kualitas perairan, overfishing, dan manajemen perikanan yang kurang baik. Suatu manajemen perikanan yang baik, didapatkan banyak informasi, dan salah satu informasinya adalah mengenai spasial dan temporal kegiatan area tangkapan ikan, seperti intensitas dan variabilitasnya [3].

Dalam bidang kelautan, konsep area mengacu pada kawasan kegiatan tangkapan serta konsentrasi biomassa yang tinggi karena kebiasaan menangkap ikan, dinamika populasi, kondisi cuaca, atau kondisi lingkungan tertentu yang membentuk produktivitas ekosistem yang tinggi pada suatu area.

Disamping itu pula pemerintah juga telah memberikan peluang kepada daerah untuk dapat memberikan muatan-muatan lokal yang dapat meningkatkan dan mempertahankan budaya di masing-masing daerah secara umumnya dan provinsi Aceh secara khususnya[1].

Berbicara mengenai kebudayaan daerah Aceh tidak terlepas dari salah satu komponen budaya yaitu kesenian. Salah satu kesenian yang menjadi ciri khas Aceh adalah musik Aceh. Dalam mempertahankan pengetahuan budaya kesenian Aceh dan daerah lainnya saat ini, pemerintah daerah telah membuat buku kesenian bermuatan lokal dalam bentuk bukubuku pelajaran praktis.

Salah satu pembelajaran pengetahuan seni yang diterbitkan oleh pemerintah adalah pengenalan alatalat musik tradisional Aceh baik dalam bentuk brosur maupun media cetak yang diterbitkan oleh musium Aceh[1].

Penerapan model pembelajaran pengenalan alatalat musik tradisional Aceh yang berbasis buku merupakan model konvensional yang telah lama digunakan. Akan tetapi penerapan model 
pembelajaran konvensional khususnya pada pelajaran pengenalan alat musik tradisional masihlah belum begitu efektif. Perlu sebuah model pembelajaran berbasis multimedia yang dapat mengajak pembaca untuk mengetahui dengan proses mendengar dan melihat objek langsung secara visual bagaimana bentuk dan suara dari alat musik tradisional Aceh tersebut. Berdasarkan latar belakang, maka penelitian ini bertujuan untuk merancang dan membangun suatu media interaktif berbasis konten animasi dua dimensi yang dapat digunakan sebagai media untuk menyajikan informasi tentang alat musik etnik Aceh sehingga alat-alat music tersebut dapat terlestarikan.

\section{Tinjauan Pustaka}

Dalam penginderaan jauh didapat data hasil observasi yang disebut citra. Citra dapat diartikan sebagai gambaran yang tampak dari suatu objek yang sedang diamati, sebagai hasil liputan atau rekaman suatu alat pemantau. Citra sebagai gambaran rekaman suatu objek yang didapat dengan cara optik, elektro optik, optik mekanik atau elektronik. Sebuah citra terbentuk dalam format digital yang tersusun dari beberapa unsur gambar atau disebut piksel.

Interpretasi citra adalah proses pengkajian citra melalui proses identifikasi dan penilaian mengenai objek yang tampak pada citra. Dengan kata lain, interpretasi citra merupakan suatu proses pengenalan objek yang berupa gambar (citra) untuk digunakan dalam disiplin ilmu tertentu seperti Geologi, Geografi, Ekologi, Geodesi dan disiplin ilmu lainnya. Pengenalan obyek adalah bagian penting dalam upaya untuk menginterpretasikan citra. Delapan unsur yang menjadi karakteristik penting dari obyek pada citra yang digunakan sebagai interpretasi citra. Kedelapan unsur tersebut ialah warna (color) dan rona (tone), bentuk (shape), ukuran (size), bayangan (shadow), tekstur (texture), pola (pattern), situs (site), dan asosiasi (association). Diantara kedelapan unsur tersebut, warna/rona merupakan hal yang paling dominan. Rona adalah tingkat kecerahan/kegelapan suatu obyek yang terdapat pada citra. Warna adalah wujud yang tampak oleh mata dengan menggunakan spektrum sempit, lebih sempit dari spektrum tampak. Semua elemen tersebut digunakan oleh pakar interpretasi citra yang dapat memperkirakan dengan cepat dan akurat [4].

Satelit penginderaan merupakan sebuah benda diangkasa yang berputar mengikuti rotasi bumi. Satelit dibagun untuk kemudian diluncurkan ke luar angkasa menggunakan roket. Saat masuk orbit satelit akan mengelilingi bumi. Orbit merupakan jalur lintasan yang dilalui satelit saat melintas bumi dan di tempatkan sejajar digaris ekuador. Grafitasi bumi akan mempertahankan posisi satelit agar tetap berada di orbitnya pada ketinggian tertentu. Satelit agar selalu berada pada area bumi yang sama atau disebut jejak satelit di suatu Negara atau daerah tertentu saja. Satelit menggunakan gelombang radio elektromagnetik yang mengirimkan sinyal keantena yang berada di bumi atau menangkap sinyal dan memproses informasi yang masuk didalamnya.

Perkembangan teknologi penginderaan jauh (Remote Sensing), menjadikannya sebagai Metodologi Survey yang secara kontinyu dapat dimanfaatkan untuk menyajikan kondisi laut. Penginderaan jauh dapat dimanfaatkan untuk aplikasi kelautan terutama lapisan permukaan laut, salah satunya adalah satelit Aqua MODIS (Aqua-Terra Moderate Resolution Imaging Spectroradiometer).

Satelit Aqua MODIS yang dalam bahasa latin berarti air adalah satelit ilmu pengetahuan tentang bumi milik NASA. Satelit Aqua MODIS mempunyai misi mengumpulkan informasi tentang siklus air di bumi termasuk penguapan dari samudera, uap air di atmosfer, awan, presipitasi, kelembaban tanah, es yang ada di laut, es yang ada di darat, serta salju yang menutupi daratan. Variabel yang diukur oleh satelit Aqua MODIS antara lain aerosol, tumbuhan yang menutupi daratan, fitoplankton dan bahan organik terlarut di lautan, serta suhu udara, daratan dan air. Satelit Aqua MODIS membawa sensor MODIS yang mempunyai 36 kanal spektral dengan kisaran panjang gelombang antara $0,4 \mu \mathrm{m}$ sampai $14,4 \mu \mathrm{m}$. Data tersebut ditransmisikan melalui frekuensi $8160.0 \mathrm{MHz}$ [5].

\section{Metode Penelitian}

Metode ekstraksi informasi menggunakan analisis dan klasifikasi multispektral yang memanfaatkan value (nilai) dari respon spektral citra sebagai dasar penentuan jenis atau karakteristik sebuah obyek kenampakan muka bumi pada citra tersebut. Data sekunder yaitu hasil tangkapan nelayan lokal dari enam titik koordinat area pancing, yang didaratkan di pelabuhan TPI Calang Kecamatan Krueng Sabee bulan april, mei dan juni tahun 2018. Metode deskriptif kuantitatif digunakan untuk mengetahui nilai variabel mandiri, baik satu variabel atau lebih (independen) tanpa membuat perbandingan, atau menghubungkan dengan variabel yang lain. 


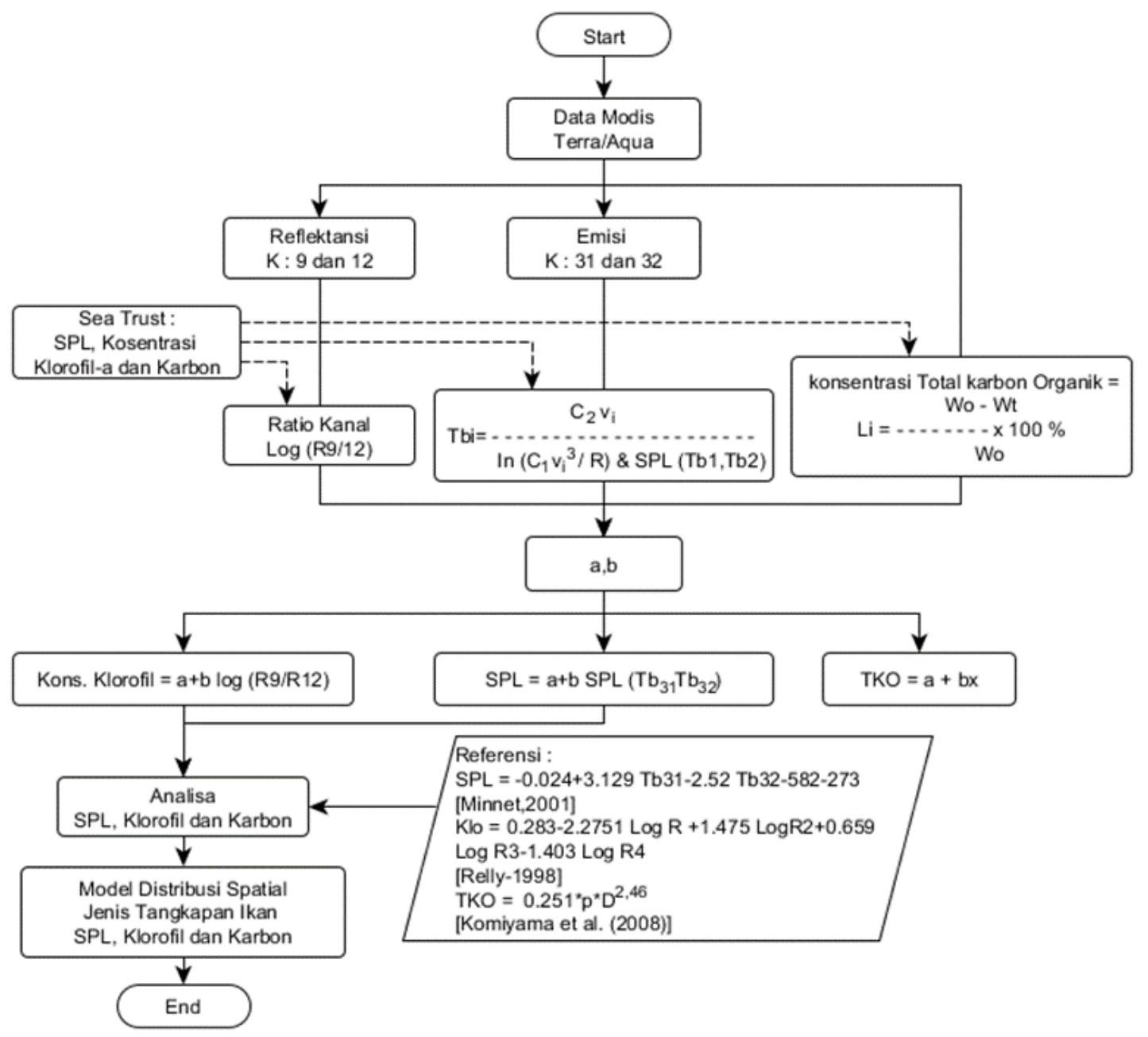

Gambar 1. Diagram Alir Penelitian

\subsection{Teknik Sampling}

Alat tangkap yang digunakan yaitu pancing ulur. Pada prinsipnya pancing ulur terdiri dari dua komponen utama yaitu tali (line) dan mata pancing (hook), alat tangkap pancing ulur digolong ke dalam Fishing With Line yang dilengkapi dengan mata pancing no. 6-7, tali utama yaitu senar no. 50-60 dengan panjang $30-40 \mathrm{~m}$, dan pemberat $\pm 1000 \mathrm{~g}$. umpan hidup yang digunakan adalah udang. Penangkapan ikan dilakukan dalam dua sesi, pagi dan sore. Sesi pagi mulai dari jam 08.30 Wib sampai dengan jam $12.00 \mathrm{Wib}$ dan sesi sore mulai jam 13.30 Wib sampai dengan jam 18.30 Wib. 5 kali tangkapan/hari.

Penentuan sampel ikan didasarkan hasil tangkapan yang dominan. Data yang diambil dari sampling komposisi hasil tangkapan yaitu nama ikan, jumlah ikan (ekor), bobot ikan (kg). Selanjutnya melakukan pengumpulan data citra SPL, klorofil-a dan TKO hasil deteksi satelit Aqua Modis pada perairan Pulo Ranggah dan sekitarnya.

\subsection{Pengolahan data Satelit}

Data citra yang diolah adalah citra yang mencakup lintang bujur sesuai dengan cakupan area yang diteliti. Pemotongan citra bertujuan untuk membatasi ruang lingkup spasial pada citra sesuai dengan area yang diamati, proses pemotongan menggunakan program SeaDAS. Dalam proses pemotongan citra perlu dimasukkan nilai pixel/line awal dan nilai pixel/line akhir serta nilai lintang/bujur awal dan akhir.

Penentuan Klorofil-a menggunakan sensor karakteristik Ocean Color yaitu daerah visible sinar biru dan sinar hijau. Sinar hijau yang dipantulkan dari permukaan laut membawa informasi mengenai kosentrasi klorofil-a yang dideteksi oleh sensor. Perhitungan kosentrasi klorofil-a dengan menggunakan parameter band 9 dan 12. Penentuan Suhu Permukaan Laut dilakukan dengan pengecekan pada citra piksel yang berawan, selanjutnya dilakukan perhitungan SST pada piksel yang bebas awan.

Analisis korelasi pola distribusi kosentrasi Klorofil-a, Suhu Permukaan Laut dan total karbon oksida dalam bentuk peta kontur sebaran suhu permukaan laut, kosentrasi Klorofil-a dan Total Karbon Organik. Tujuan pengolahan citra ini untuk memunculkan informasi yang dibutuhkan dalam penelitian berupa fenomena- fenomena yang terjadi dalam di permukaan laut. Hasil selanjutnya dilakukan 
proses interpretasi guna mendapatkan informasi daerah penangkapan ikan.

Alur diagram alir pengolahan citra data satelit untuk penentuan Suhu Permukaan Laut, kosentrasi
Klorofil-a dan Total Karbon Organik dapat dilihat pada Gambar 2.

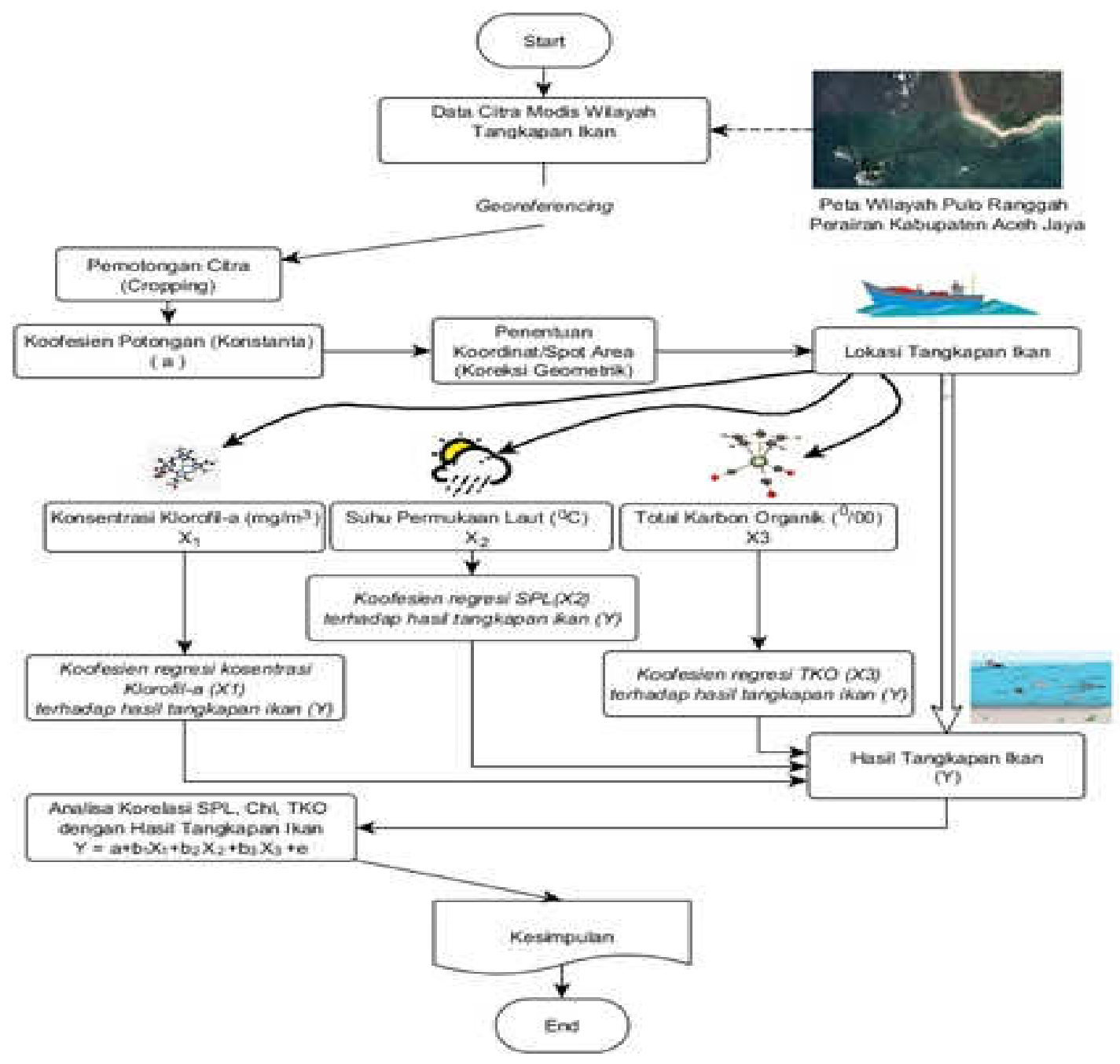

Gambar 2. Diagram Alir Pengolahan Data Satelit

\section{Hasil Dan Pembahasan}

\subsection{Ekstraksi Citra Satelit}

Ekstraksi bertujuan untuk mendapatkan sebaran suhu permukaan laut, nilai klorofil-a dan Total Karbon Organik dari hasil penelitian yang telah dilakukan pada perairan Pulo Ranggah Kabupaten Aceh Jaya di 6 (enam) stasiun. Ekstraksi dari citra satelit Moderate Imaging Spektroradiometer (MODIS), dengan perekaman April, Mei dan Juni tahun 2018 menjadi acuan analisis hubungan suhu permukaan laut, klorofil-a, Total Karbon Organik terhadap hasil tangkapan ikan.

\subsection{Suhu Permukaan Laut}

Sebaran Suhu Permukaan Laut (SPL) di perairan Pulo Ranggah Kabupaten Aceh Jaya berdasarkan hasil ekstraksi citra satelit Aqua dan Terra MODIS. Pada Citra Aqua MODIS didapat rata-rata sebaran suhu permukaan laut pada bulan April sebesar 30.590C, Mei 30.72 dan Juni 31.640C. Untuk Citra Terra MODIS rata-rata SPL pada bulan April 30.490C, Mei 30.610C dan Juni 30.710C. Untuk lebih jelasnya lihat Tabel 1 .

Berdasarkan sebaran suhu permukaan laut yang didapat, SPL $\left({ }^{\circ} \mathrm{C}\right)$ untuk area tangkapan ikan pada Citra Aqua MODIS didapat suhu tertinggi berada pada area Kareng Pulo Ranggah di bulan Juni dengan suhu $31.77{ }^{\circ} \mathrm{C}$ dan suhu terendah pada area Kareng Burok Tairo di bulan Mei yaitu $30.40{ }^{\circ} \mathrm{C}$. Pada Citra Terra MODIS didapat suhu tertinggi berada pada area Kareng Pulo Ranggah di bulan Mei dengan suhu $31.12{ }^{\circ} \mathrm{C}$ dan suhu terendah pada area Kareng Burok Tairo di bulan April dengan suhu $30.38{ }^{\circ} \mathrm{C}$. Sebaran Suhu Permukaan Laut untuk 6 stasiun area tangkapan ikan dapat dilihat pada Gambar 3. 


\subsection{Citra Sebaran SPL}

Dari hasil pembentukan citra suhu permukaan laut berdasarkan dari hasil ekstraksi. Hasil pengolahan data kontur menunjukkan warna biru mendekati biru langit mencerminkan sebaran suhu permukaan laut perairan bersifat rendah. Warna permukaan laut akan berubah dari biru langit menjadi hijau, kekuningan, bahkan menjadi merah dan putih, merefleksikan terjadinya perubahan tingkat sebaran suhu permukaan laut semakin tinggi. Hasil sebaran suhu permukaan laut Aqua MODIS dapat dilihat pada Gambar 4.

Tabel 1. Sebaran Suhu Permukaan Laut (SPL)

\begin{tabular}{|l|r|l|c|c|c|c|}
\hline \multicolumn{3}{|c|}{ Suhu Permukaan Laut $\left({ }^{\circ}\right.$ C) } & \multicolumn{4}{c|}{ Citra Aqua MODIS } \\
\hline \multicolumn{1}{|c|}{ Area Tangkapan } & Longitude & Latitude & April & Mei & Juni & Rata-rata \\
\hline Kareng Burok Pulo Pasi & 95.52083 & 4.6875000 & 30.55 & 30.70 & 31.53 & 30.93 \\
\hline Kareng Pak Akong & 95.47916 & 4.6458335 & 30.44 & 30.64 & 31.55 & 30.87 \\
\hline Kareng Laot Bineh & 95.52083 & 4.6458335 & 30.56 & 30.81 & 31.68 & 31.02 \\
\hline Kareng Pulo Ranggah & 95.56249 & 4.6458335 & 30.73 & 31.12 & 31.77 & 31.21 \\
\hline Kareng Burok Tairo & 95.52083 & 4.6041665 & 30.55 & 30.40 & 31.65 & 30.87 \\
\hline Kareng Lungkap Menjen & 95.56249 & 4.6041665 & 30.72 & 30.66 & 31.64 & 31.01 \\
\hline \multicolumn{3}{|c|}{ Rata-rata SPL Berdasarkan Bulan } & $\mathbf{3 0 . 5 9}$ & $\mathbf{3 0 . 7 2}$ & $\mathbf{3 1 . 6 4}$ & \\
\hline
\end{tabular}

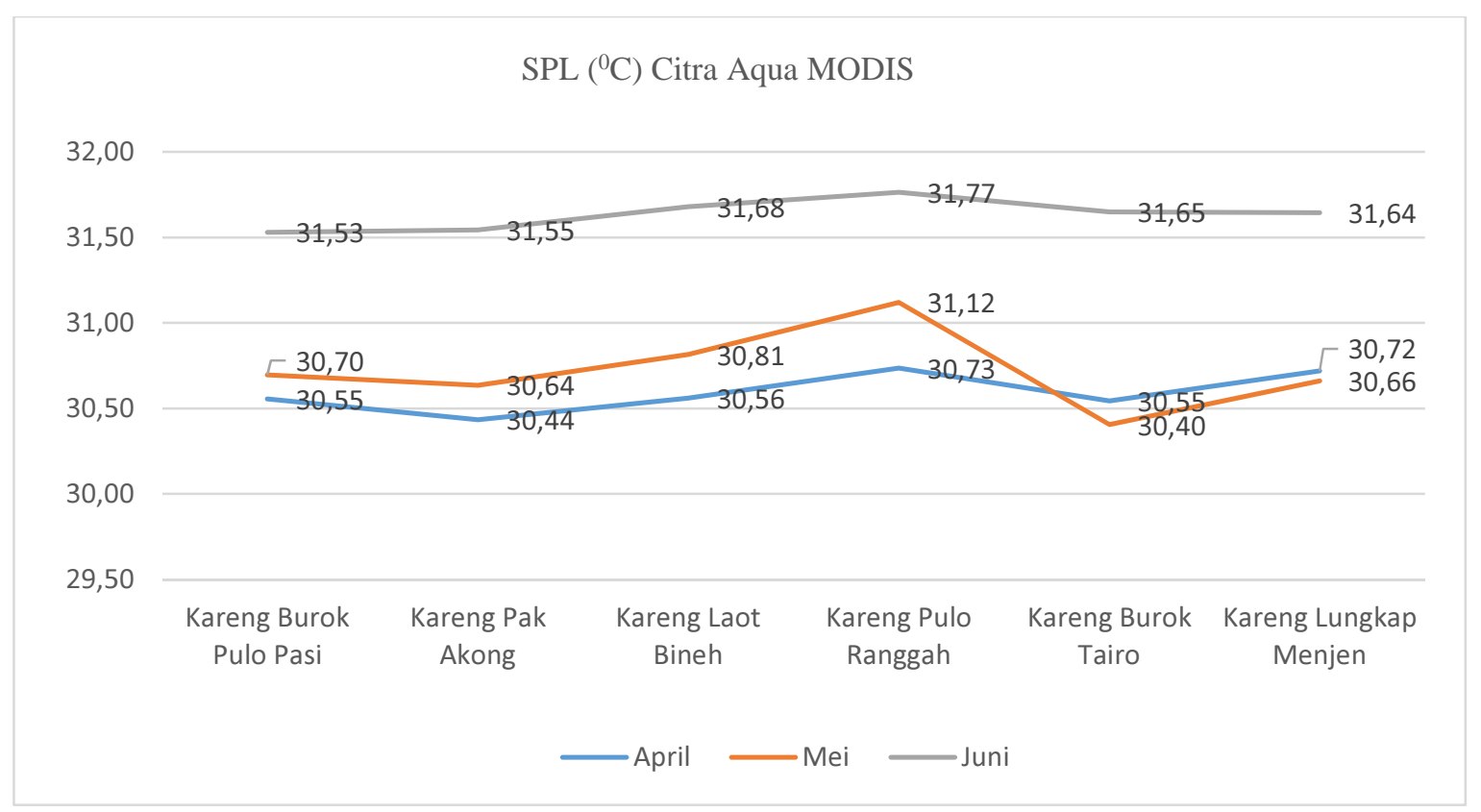

Gambar 3. Suhu Permukaan Laut Aqua MODIS berdasarkan Area Tangkapan Ikan Bulan April - Juni tahun 2018

\subsection{Data hasil tangkapan ikan}

Hasil tangkapan ikan oleh nelayan tradisional dengan pancing ulur di kawasan Pulau Ranggah dan sekitarnya dari enam area yaitu Sport 1 (Kareng Burok Pulo Pasi), Spot 2 (Kareng Pak Akong), Spot 3 (Kareng Laot Bineh), Spot 4 (Kareng Pulo Ranggah), Spot 4 (Kareng Burok Tairo),Spot 5 (Kareng Burok Tairo), Spot 6 (Kareng Lungkap Menjen).
Dari tiga bulan yang dilakukan penelitian, hasil tangkapan ikan yang pada 6 titik area, Bulan April jumlah tangkapan terbanyak didapat pada area Kareng Lungkap Menjen spesies ikan Rambai dengan berat $48.5 \mathrm{~kg}$. Titik area tangkapan yang tidak mendapatkan hasil pada kawasan Kareng Pulo Ranggah dengan hasil tangkapan $0 \mathrm{~kg}$.

Pada Bulan Mei jumlah tangkapan terbanyak didapat pada area Kareng Lungkap Menjen spesies ikan Kwee dengan berat $47.9 \mathrm{~kg}$. dan area tidak 
mendapatkan hasil tangkapan di kawasan Kareng Pulo Ranggah dengan hasil tangkapan $0 \mathrm{~kg}$. Selanjutnya dilakukan penelitian pada bulan Juni, dimana spesies terbanyak yaitu Rambai pada area Kareng Burok Pulo Pasi dengan berat 97 kg. Untuk lebih jelasnya hasil tangkapan dari tiga bulan dapat dilihat pada Gambar 5.
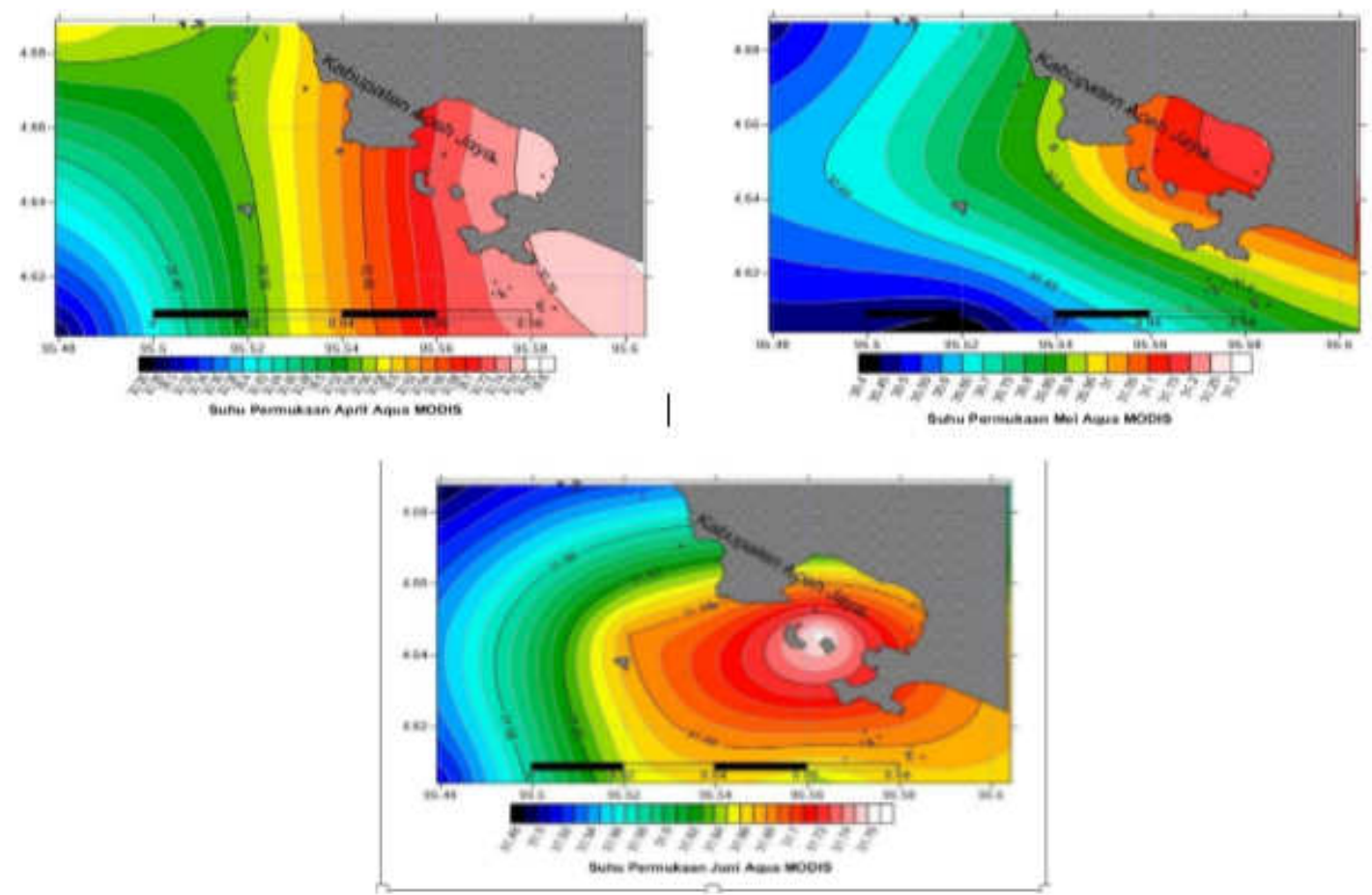

Gambar 4. Citra Sebaran Suhu Permukaan Laut Aqua

\subsection{Suhu Permukaan Laut dengan Hasil Tangkapan}

Berdasarkan hasil analisis data suhu permukaan laut dengan Citra Aqua untuk bulan April, Mei dan Juni tahun 2018 dari 6 lokasi penelitian. Rata-rata suhu permukaan laut untuk Citra Aqua MODIS bulan April 30,59 0C, bulan Mei 30,72 0C dan bulan Juni 31,64 0C. Dari hasil tangkapan yang didapat, rata-rata menunjukkan bahwa jumlah prediksi tangkapan ikan SPL Citra Aqua berada pada suhu 30,72 - 31,64 0C di bulan Juni dan jumlah tangkapan ikan terendah berada pada suhu 30,50 - 30,59 0C dibulan April.

\subsection{Sebaran Klorofil-a}

Berdasarkan hasil analisis sebaran Klorofil-a dengan jumlah tangkapan ikan untuk bulan April, Mei dan Juni tahun 2018 dari 6 lokasi penelitian. Rata-rata sebaran kandungan klorofil-a pada bulan April menunjukkan Citra Aqua Modis sebaran nilai klorofil-a $0.40 \mathrm{mg} / \mathrm{m} 3$, pada bulan Mei sebaran Klorofil-a menunjukkan $0.36 \mathrm{mg} / \mathrm{m} 3$ dan bulan Juni sebaran Klorofil-a menunjukkan $1.04 \mathrm{mg} / \mathrm{m} 3$. Dari hasil kandungan klorofil-a didapat bahwa kandungan klorofile-a tertinggi pada bulan juni dan jumlah tangkapan ikan terbanyak terjadi pada bulan Juni dengan jumlah tangkapan $672.60 \mathrm{Kg}$.

\subsection{Sebaran Total Karbon Organik dengan Hasil Tangkapan Ikan}

Sebaran kandungan total karbon organik rata-rata kandungan nilai Total Karbon Oranik pada Citra Aqua Modis pada bulan April menunjukkan nilai 11,6 $\%$, Pada bulan Mei menunjukkan 11,8\%, Sedangkan pada bulan Juni nilai Total Kabon Organik untuk Citra Aqua 18,2\%. Dari hasil penelitian tangkapan ikan untuk tiga bulan didapat jumlah tangkapan ikan pada bulan April 245,00 Kg, bulan Mei jumlah tangkapan 462.60 dan Juni dengan jumlah 672,60 Kg. Hubunan Sebaran Total Karbon Organik berpengaruh terhadap jumlah Tangkapan Ikan, dimana Total Karbon Organik tertinggi terdapat pada Area Kareng Burok Pulo Pase dan jenis tangkapan ikan terbanyak juga tedapat pada Area Kareng Burok Pulo Pase.

Untuk perbandingan masing - masing hasil SPL, klorofil - a dan juga karbon organik, maka dapat dilihat pada Gambar 6. 

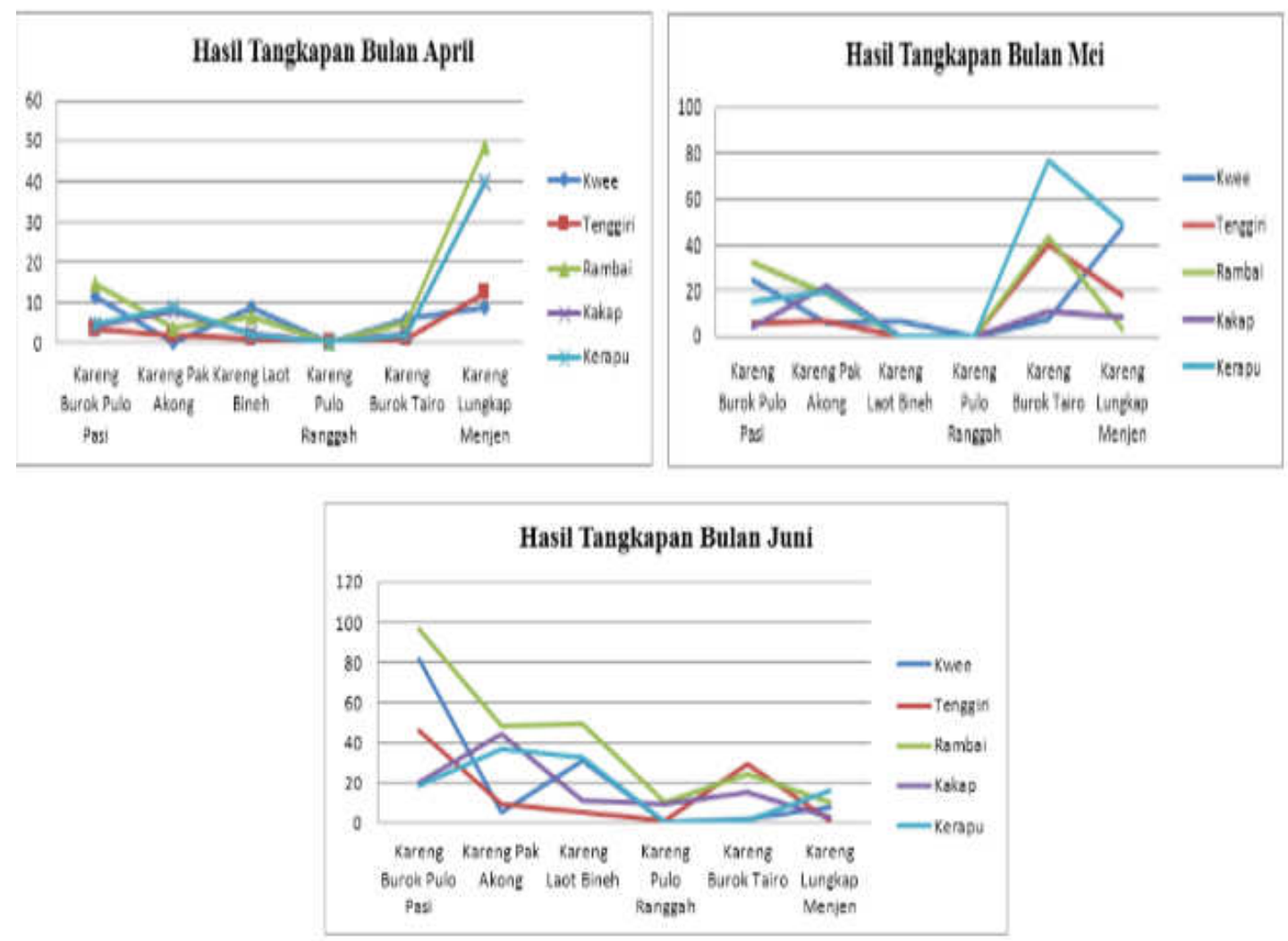

Gambar 5. Hasil tangkapan Bulan April - Bulan Juni 2018

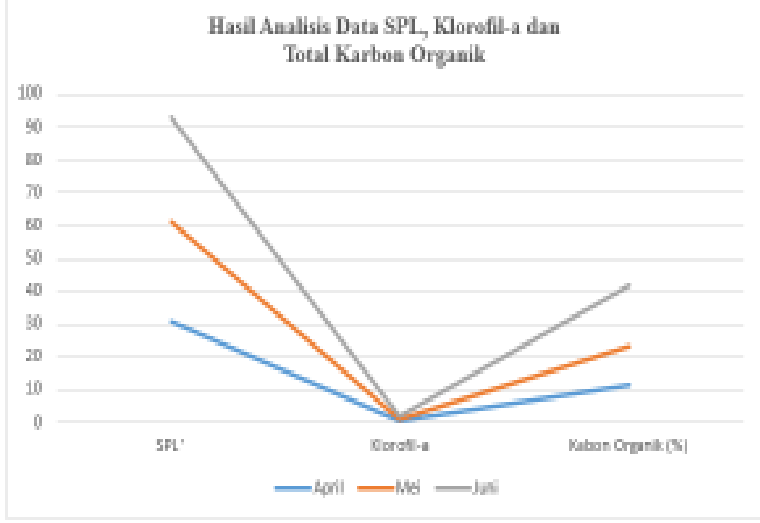

Gambar 6. Hasil Analisis data SPL, Klorofil-a dan karbon organik.

\section{Kesimpulan Dan Saran}

Berdasarkan hasil penelitian yang diperoleh, dapat diambil kesimpulan sebagai berikut :

1. Korelasi yang signifikan terjadi antara suhu permukaan citra Aqua Modis dengan tangkapan ikan Tenggiri, Rambai, dan Kerapu pada bulan Mai, dan pada bulan Juni dengan tangkapan ikan Rambai. Sedangkan pada bulan April tidak memiliki korelasi yang siginifikan.

2. Korelasi yang signifikan terjadi anatara Klorofila dari citra Aqua Modis dengan tangkapan ikan Kerapu dan ikan Tenggiri pada bulan Mai.
Sedangkan pada bulan April dan Juni tidak memiliki korelasi yang signifikan.

\section{Daftar Pustaka}

[1].Barnes, R. and D. Metcalf. Current legal developments the European Union: the marine strategy frame- work directive. IJMCL., 25:8191. 2010

[2].Batista, M.I., B. Horta e Costa, L. Gonc salves, M. Henriques, K. Erzini, J.E. Caselle, E.J. Gonc,alves, and H.N. Cabral. "Assessment of catches, landings and fishing effort as useful tools for MPA management". Fish. Res. 172:197-208. doi:10.1016/ j.fishres.2015.07.020. 2015.

[3].Jalali, M.A., D. Ierodiaconou, H. Gorfine, J. Monk, and A. Rattray. "Ex-ploring spatiotemporal trends in commercial fishing effort of an abalone fishing zone: a GIS-based hotspot model". PLoS ONE, 10(5):65-72. doi:10.1371/journal.pone.0122995. 2015.

[4].Colwell, R.N., "Manual of Photographic Interpretation, American Society for Photogrammetry \& Remote Sensing”, 1997

[5].https://en.wikipedia.org/wiki/Vandenberg_Air_F orce_Base, diakses Tanggal 20 Desember 2018

[6]. Zulfan, F. Arnia , R. Muharar. Deteksi Pemalsuan Citra dengan Teknik Copy-Move Menggunakan Metode Ordinal Measure dari Koefisien Discrete Cosine Transform. Jurnal Nasional Teknik Elektro, 30;5(2):165-74, Maret 2016 
